зование ягодно-овощных соков в технологии молочного пудинга // Современные тенденции развития науки и производства: материалы III Междунар. науч.-практ. конф. - Донецк, 2016. - С. 167-169.

10. Келдибекова Д.А., Мамаев А.В. Перспективы применения пектина при разработке кисельного молочного продукта с сорбционными свойствами // Актуальные проблемы науки XXI века: III Междунар. конф. - 2015. - С. 6-9.

Меркулова Анастасия Андреевна, магистрант, Орловский государственный аграрный университет имени Н.В. Парахина. Россия.

Родина Наталья Дмитриевна, канд. биол. наук, доцент кафедры «Продукты питания животного происхождения», Орловский государственный аграрный университет имени Н.В. Парахина. Россия.

Сергеева Екатерина Юрьевна, канд. техн. наук, до- иент кафедры «Продукты питания животного происхождения», Орловский государственный аграрный университет имени Н.В. Парахина. Россия.

Мамаев Андрей Валентинович, $\partial-p$ биол. наук, проф. кафедры «Продукты питания животного происхождения», Орловский государственный аграрный университет имени Н.В. Парахина. Россия.

Цикин Сергей Сергеевич, канд. техн. наук, доцент кафедры «Продукты питания животного происхождения», Орловский государственный аграрный университет имени Н.В. Парахина. Россия.

302019, г. Орел, ул. Генерала Родина, 69.

Тел.: (4862) 76-15-17.

Ключевые слова: молочный мусс; джем; рябина обыкновенная; органолептические показатели, кислотность; образцы молочного мусса.

\title{
DEVELOPMENT AND EVALUATION OF QUALITY INDICATORS OF MILK MOUSSE WITH A FILLER - SORBUS
} AUCUPARIA

Merkulova Anastasiya Andreevna, Magistrandt, Orel State Agrarian University named after N.V. Parakhin. Russia.

Rodina Natalya Dmitrievna, Candidate of Biological Sciences, Associate Professor of the chair "Food of Animal Origin", Orel State Agrarian University named after N.V. Parakhin. Russia.

Sergeeva Ekaterina Yurievna, Candidate of Technical Sciences, Associate Professor of the chair "Food of Animal Origin", Orel State Agrarian University named after N.V. Parakhin. Russia.

Mamaev Andrey Valentinovich, Doctor of Biological Sciences, Professor of the chair "Food of Animal Origin", Orel State Agrarian University named after N.V. Parakhin. Russia.

Tsikin Sergey Sergeevich, . Candidate of Technical Sciences,
Associate Professor of the chair "Food of Animal Origin", Orel State Agrarian University named after N.V. Parakhin. Russia.

Key words: dairy mousse, jam; Sorbus aucuparia; organoleptic indicators; acidity, samples of milk mousse.

The authors developed the recipe of a few samples of milk mousse with filler-jam from the berries of Sorbus aucuparia. All samples were tested by organoleptic and physical and chemical parameters. Increase in acidity was observed; scoring indicators of milk mousse with jam from berries of Sorbus aucuparia was produced.

\section{ЭКСПЕРИМЕНТАЛЬНОЕ ИССЛЕДОВАНИЕ МОЩНОСТИ ДЛЯ ПРИВОДА ПНЕВМОВИНТОВОЙ УСТАНОВКИ ПРИ ТРАНСПОРТИРОВАНИИ ЗЕРНА}

УдК 631.861

\author{
ПАВЛОВ Павел Иванович, Саратовский государственный аграрный университет имени \\ Н.И. Вавилова
}

КОРСАК Виктор Владиславович, Саратовский государственный аграрный университет имени Н.И. Вавилова

ОВЧИННИКОВА Татьяна Владимировна, Саратовский государственный аграрный университет имени Н.И. Вавилова

В статъе изложены методика и результаты экспериментальных исследований мощности для привода пневмовинтовой установки при транспортировании зерна. Указаны приборы и способы задавания и замера основных параметров. Представлены уравнения регрессии и графические зависимости влияния скорости осевого воздушного потока, частоты вращения и шага шнека. Установлены значения указанных параметров, при которых мощность, необхоимая для привода, имеет минимальное и максимальное значение.

Введение. Пневмовинтовая установка применяется для транспортирования зерна на зерноскладах, хранилищах, элеваторах. Благодаря одновременному воздействию на зерно шнека и потока воздуха в пневмовинтовой установке достигается более высокая производительность в сравнении со шнековым транспортером [2, 3, 5-8, 10]. Другим важным параметром оценки работы является мощность, необходимая для привода рабочих органов. Суммарная мощность $\mathrm{P}_{\Sigma}$, Вт, для транспортирования зерна пневмовинтовой установкой включает в себя мощность, необходимую для привода шнека, и мощность для привода вентилятора, создающего воздушный поток $[2,4]$. 
Методика исследований. Методикой экспериментального исследования влияния частоты вращения и шага шнека, а также скорости воздушного потока на приводную мощность предусматривалось проведение двухфакторных экспериментов. Шаг задавался относительной величиной - коэффициентом шага $K_{p}$, равным отношению величины шага к диаметру шнека. Изготовлены 4 шнека одинакового диаметра, но с различным шагом. Исследования проводили со шнеками диаметром 90 мм с коэффициентом шага $K_{p}=0,8 ; 0,95 ; 1,1 ; 1,25$. Режимные параметры: частота вращения шнека задавалась сменой шкивов ременной передачи и составляла $n=480,560,640,720,800$ мин $^{-1}$. Разряжение, создаваемое вентилятором, изменялось с помощью заслонки, замеры величины разряжения производили микроманометром, скорость воздуха замеряли на выходе из вентилятора и входе в кожух с помощью крыльчатого анемометра, время транспортирования фиксировали секундомером [2]. Замеры силы тока и напряжения в цепи электродвигателей позволяли рассчитать мощность, потребляемую шнеком и вентилятором. Поскольку основной характеристикой зерна и примесей является критическая скорость витания, то в планировании эксперимента удобнее использовать не величину разряжения, а скорость потока воздуха. Помимо этого скорость потока воздуха замеряется более простыми методами с использованием крыльчатого анемометра.

Результаты исследований. Результатом обработки опытных данных являлось уравнение регрессии. После получения уравнения регрессии определяли стандартное отклонение (ошибка) опыта и модели. Вычисляли значение критерия Фишера фактическое $F_{\text {факт }}$, которое сравнивали с табличным значением критерия Фишера $F_{05}$ и $F_{01}[2]$.

В результате проведенных экспериментальных исследований установлено влияние скорости воздушного потока v, м/с, частоты враще-
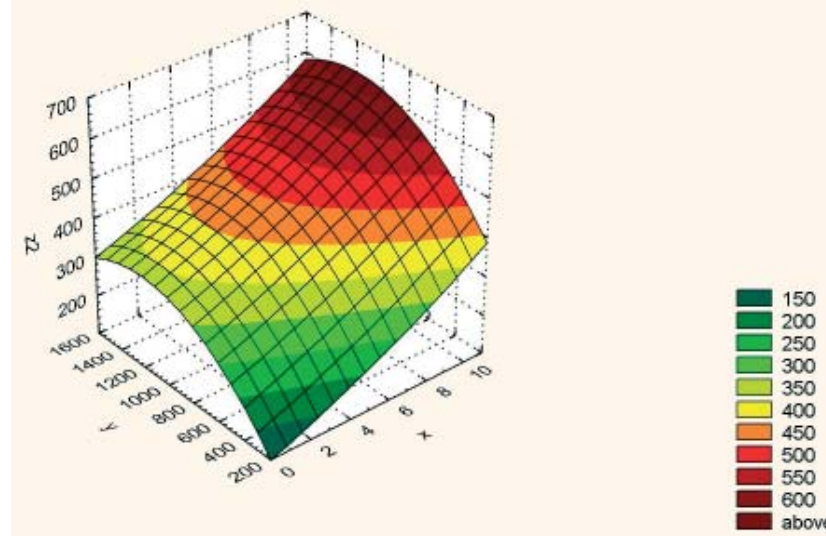

Рис. 1. Зависимость суммарной мощности на привод пневмовинтовой установки от скорости воздушного потока х и частоты вращения шнека у

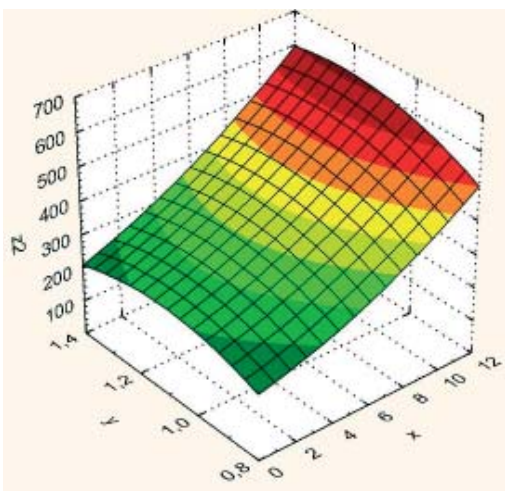

Рис. 2. Зависимость суммарной мощности на привод пневмовинтовой установки от скорости воздушного потока х и коэффициента шага шнека у при транспортировании зерна пшеницы

ния $n$, мин $^{-1}$, и шага шнека $p$, мм, на суммарную мощность привода пневмовинтовой установки. По результатам обработки экспериментальных данных получены уравнения регрессии $(1,2)$. Уравнение (1) описывает зависимость приводной мощности от скорости воздушного потока и частоты вращения шнека.

$$
\begin{aligned}
P= & -6,035+18,841 v+0,574 n+0,664 v^{2}- \\
& -2,121 \cdot 10^{-4} v n-2,403 \cdot 10^{-4} n^{2} .
\end{aligned}
$$

Графически зависимость представлена на рис. 1.

Уравнение (2) описывает зависимость приводной мощности от скорости воздушного потока и шага шнека.

$$
\begin{gathered}
P=-492,52+3,093 v+1340,8 \cdot K_{p}+1,074 v^{2}+ \\
+11,708 v K_{p}-600 v^{2}
\end{gathered}
$$

В виде поверхности отклика уравнение (2) представлено на рис. 2.

Анализ уравнений регрессии и графических зависимостей показывает, что влияние скорости осевого воздушного потока на суммарную мощность привода пневмовинтовой установки имеет аналогичный характер при всех значениях частоты вращения шнека.

Увеличение скорости воздушного потока приводит к росту суммарной мощности. При частоте вращения шнека 840 мин $^{-1}$ увеличение v от нуля до 3,2 м/с приводит к росту суммарной мощности в 1,21 раза - с 310 до 376 Вт. Рост скорости с 3,2 до $6,4 \mathrm{M} /$ с приводит к росту $P_{\Sigma}$ с 376 до 458 Вт, т.е. на 21,8 \% [2].

Влияние частоты вращения шнека на суммарную приводную мощность имеет несколько другой характер (см. рис. 1). Возрастание $P_{\Sigma}$ при $n$ до $1050 \ldots 1150$ мин $^{-1}$ объясняется увеличением заполнения зерновой массой межвиткового пространства шнека за счет воздушного потока и ростом скорости ее перемещения. Максимальное значение суммарной мощности достигается при частоте вращения шнека $1050 \ldots$ 1150 мин $^{-1}$. С ростом $n$ выше указанных значений заполнение межвиткового пространства 
уменьшается и уменьшается перемещаемая масса зерна, соответственно, снижается необходимая мощность на привод.

С увеличением шага шнека суммарная мощность привода вначале возрастает, достигает максимального значения, затем снижается (см. рис. 2). При всех значениях скорости воздушного потока увеличение шага оказывает на суммарную мощность аналогичное влияние, однако имеет место увеличение значения шага, при котором суммарная мощность достигает максимального значения. При скорости осевого воздушного потока $v=3,2 \mathrm{M} / \mathrm{c} P_{\Sigma}$ достигает максимального значения 325-330 Вт при коэффициенте шага $K_{p}=1,06-1,08$. При скорости v = $=6,4 \mathrm{M} / \mathrm{c}$ коэффициент шага, соответствующий максимальной потребляемой мощности $\left(P_{\Sigma}=405-410\right.$ Вт), увеличивается до 1,09-1,1. При $\mathrm{v}=9,6 \mathrm{M} / \mathrm{c}$ наибольшая мощность требуется при коэффициенте шага $K_{p}=1,15-1,2$. Увеличение необходимой приводной мощности объясняется тем, что с ростом шага увеличивается осевая скорость перемещения зерна, на что требуются дополнительные затраты энергии.

Заключение. В результате проведенных экспериментальных исследований получены зависимости, позволяющие определять суммарную мощность, необходимую для привода пневмовинтовой установки в зависимости от скорости воздушного потока v, м/с, частоты вращения $n$, мин $^{-1}$, и шага шнека $p$, мм. Установлены минимальные и максимальные значения суммарной мощности для исследуемых конструктивно-режимных параметров.

\section{СПИСОК ЛИТЕРАТУРЫ}

1. Исследование влияния скорости горизонтального воздушного потока на производительность отделения легких примесей из зерновой массы при транспортировании / П.И. Павлов [и др.] // Аграрный научный журнал - 2016. - № 3. - С. 49-50.

2. Овчинникова T.B. Обоснование параметров и режимов работы пневмовинтовой установки для транспортирования зерна с устройством для удаления легких примесей: дисс. ... канд. тех. наук. - Саратов, 2016. - 137c.
3. Овчинникова Т.В., Павлов П.И. Результаты исследований производительности и мощности привода пневмовинтовой установки // Научное обозрение. - 2014. - № 10. - С. 18-20.

4. Овчинникова Т.В., Павлов П.И. Результаты экспериментальных исследований влияния шага шнека и скорости воздушного потока на производительность и суммарную мощность привода пневмовинтовой установки // Научное обозрение. - 2015. - № 8. С. $10-23$.

5. Павлов П.И., Салихов А.Н., Нестеров С.А. Исследование движения зерна в канале пневмовинтового конвейера / Вестник Саратовского госагроуниверситета им. Н.И. Вавилова. - 2007. - № 4. - С. 54-55.

6. Павлов П.И., Чапльнская А.А. Рациональные режимные параметры пневмоспирального транспортера // Вестник Саратовского госагроуниверситета им. Н.И. Вавилова. - 2010. - № 8. - С. 62-64.

7. Пневмовинтовая установка / Павлов П.И., Салихов А.Н., Овчинникова Т.В. // Патент на полезную модель № 91989, заявка № 2009139457/22, опуб. 10.03.2010, Бюл. № 7.

8. Пневмовинтовой конвейер / Салихов А.Н., Овчинникова Т.В., Мигунов И.А., Миленко Р.С. // Патент на полезную модель №107517, заявка № 2011114497/11, опуб. 20.08.11, Бюл. № 23.

9. Пневмовинтовая установка для подъема сыпучих грузов / Павлов П.И., Демин Е.Е., Салихов А.Н., Нестеров С.А., Кузнецов А.В. // Патент на изобретение № 2376233/ заяв. 2008119807/11; опуб. 20.12.2009, Бюл. № 35 .

10. Теоретическое обоснование конструктивно-технологической схемы пневмовинтовой установки / М.Г. Загоруйко [и др.] // Научное обозрение. - 2016. - № 4. - С. 61-65.

Павлов Павел Иванович, $\partial-p$ техн. наук, проф. кафедры «Механика и инженерная графика», Саратовский государственный аграрный университет имени Н.И. Вавилова. Россия.

Корсак Виктор Владиславович, $\partial-p$ техн. наук, проф. кафедры «Природообустройство и водопользование», Саратовский государственный аграрный университет имени Н.И. Вавилова. Россия.

Овчинникова Татьяна Владимировна, ассистент кафедры «Механика и инженерная графика», Саратовский государственный аграрный университет имени Н.И. Вавилова. Россия.

410056, г. Саратов, ул. Советская, 60.

Тел.: (8452) 74-96-50.

Ключевые слова: шнек; воздушный поток; зерно; мощность; пневмовинтовая установка.

\section{EXPERIMENTAL STUDY OF THE POWER FOR DRIVING OF A PNEUMATIC SCREW INSTALLATION DURING GRAIN TRANSPORTATION}

Pavlov Pavel Ivanovich, Doctor of Technical Sciences, professor of the chair "Mechanics and Engineering Graphics", Saratov State Agrarian University named after N.I. Vavilov. Russia.

Korsak Viktor Vladislavovich, Doctor of Technical Sciences, professor of the chair "Environmental Management and Water Use”, Saratov State Agrarian University named after N.I. Vavilov. Russia.

Ovchinnikova Tatyana Vladimirovna, Assistant of the chair "Mechanics and Engineering Graphics", Saratov State Agrarian University named after N.I. Vavilov. Russia.
Keywords: screw; airflow; grain; power; air screw installation.

The article describes the technique and results of experimental studies of power for driving of a pneumatic screw installation during grain transportation. The instruments and methods for setting and measuring the main parameters are indicated. The equations of regression and graphical dependences of the influence of the speed of the axial air flow, the speed and the pitch of the screw are presented. The values of these parameters are set, at which the power required for the drive has a minimum and maximum value. 